\title{
KURU DOLGU (DRY-CORE) CAM TOZU YÖNTEMI ILE ÜRETILEN GELENEKSEL AFRIKA CAM BONCUKLARI*
}

\section{TRADITIONAL AFRICAN GLASS BEADS PRODUCED BY DRY-CORE GLASS POWDER METHOD}

\author{
Serap Bedel Özek ${ }^{* *}$, Mustafa Ağatekin ${ }^{* * *}$
}

\section{Öz}

Afrika'da yapılmış olan çeşitli şekillerdeki boncuklar, düzenleme biçimleri, renklendirme seçenekleri ve bir araya getirme yöntemleri sayesinde, yazılı dilin yokluğunda kişilerin karmaşık bilgileri bu yolla ifade etmelerini sağlamıştır. Sembolik cam boncukların özenli biçimde seçilmesiyle; yaş, medeni durum ve ekonomik varlık gibi bilgiler dile getirilmiştir. Piyasa sisteminde, standart değerin birimleri ve takas aracı olarak da hizmet etmişlerdir. Dolayısıyla bu özellikleri sayesinde Afrika'daki boncukların, farklı kabilelerin ve toplulukların kültürel miraslarının sergilenmesinde de önemli rol oynadığı görülmektedir.

Bu makalede, Afrika Cam Boncuklarının tarihsel sürecine kısaca değinilmiş olup; Afrika'da boncuk üretiminde kullanılan "kuru dolgu (Dry-Core) cam tozu yöntemi", bu yöntem ile oluşturulan cam boncukların yapım süreci ve kullanılan araç ve gereçler hakkında bilgiler verilerek örneklerle görselleştirilmiştir.

Anahtar Kelimeler: Afrika, Cam boncuk, Afrika Boncuk Kültürü, Afrika Cam Boncuğu, Afrika Cam Tozu Boncukları.

\section{Abstract}

These beads have served as a visual transmission that communicates in a wide range of ideas and beliefs, and often as a cultural communication tool. In this context, it can be said that glass beads are objects that symbolize power, provide ease of decoration and trade, and therefore have important roles among cultures for centuries.

In this article, the history of glass beads used in African culture, Dry-Core glass powder method used in the production of beads in Africa, the process of making the glass beads created with this method and the tools and materials used are given information about the cultural value. past and present effects of these glass beads.

Keywords: African, Glass Beads, African Bead Culture, African Glass Bead, African Glass Powder Beads.

Derleme Makale // Başvuru tarihi: 06.03.2020 - Kabul tarihi: 11.06.2020.

*Bu çalışma "Geçmişten Günümüze Afrika Cam Boncukları" başlıklı tezden üretilerek, 14-16 Ekim 2019 tarihlerinde Afyonkarahisar'da, İkbal Termal Otel'de düzenlenen X. Uluslararası Katılımlı Seramik Kongresi'nde sözlü bildiri olarak sunulmuş aynı başlıklı çalışmanın genişletilmiş şeklidir.

${ }^{* *}$ Arş. Gör., Ondokuz Mayıs Üniversitesi, Güzel Sanatlar Fakültesi, Seramik- Cam Bölümü, serap.bedel@omu.edu.tr, https://orcid.org/0000-0002-0440-813X.

***Prof., Anadolu Üniversitesi, Güzel Sanatlar Fakültesi, Cam Bölümü, magatekin@anadolu.edu.tr, https://orcid.org/0000-0002-9002-8378. 
SDÜ ART-E

Güzel Sanatlar Fakültesi Sanat Dergisi

Haziran'20 Cilt:13 Sayı:25

ISSN 1308-2698

\section{Giriş}

Cam boncuklar, farklı üretim teknikleri ve farklı tasarımlarla asırlar boyunca büyük değişimler yaşamıştır. Dolayısıyla her cam boncuğun kendine ait bir değeri ve birçoğunun arkasında da ilginç hikayeleri vardır (Life on a String 35 Centuries of the Glass Bead, Web, 2015). Afrika'da ise geçmişten günümüze kadar cam boncuğun yeri oldukça önemli bir yere sahip olmuştur. Geçmişte ticaret amacıyla Afrika'nın farklı ülkelerine giren cam boncuklar daha sonra Afrika halkı tarafından üretilmiş ve ticaretine devam edilmiştir. Afrika bölgesinin her ülkesinde farklı türde ve teknikte cam boncuklar üretilmiş olup, hepsi de ülkeye özgü özel parçalar olmuşlardır. Özellikle Afrika'nın batı kıyısı Gana'da hala birçok türde cam boncukların üretimine devam edilmekte ve bu boncukların birçoğu da "Kuru Dolgu" (Dry-Core) cam tozu yöntemi ile üretilmektedir. Gana'da sayılı birkaç cam ocağı bulunmakta ve cam boncuk üretimi bölgede yaşayan insanların geçim kaynağını sağlamaktadır.

\section{Afrika'daki Cam Boncuğun Geçmişi}

Birbirinden farklı malzemelerle birlikte kullanılabilen ve içinde bulunduğu zamanın teknolojisi ile oluşturulan cam boncuklar, taşımadaki kolaylığı ve süslemedeki doğal şöhretleriyle birlikte kültürel bilginin karmaşık bir dizisini iletmede ideal araçlar olarak var olmuşlardır. (Life on a String 35 Centuries of the Glass Bead, Web, 2015). Boncukların kökenini, stillerini ve teknolojilerini keşfetmenin yanı sıra bundan sonraki ilerlemelerini izlemek kültürler arasındaki ilişkilerini gözler önüne sermektedir.

Afrika Cam boncuklarının tarihsel geçmişine baktığımızda; çoğunlukla 8. yy.'da ve Mozambik kıyısındaki Villancous'tan Kuzey Kenya kıyılarına kadar arkeolojik bölgelerde büyük miktarlarda rastlandığı bilinmektedir.

Afrika yüzyıllar boyunca milyonlarca cam boncuğun hedefi olmuş ve pek çoğu, bulundukları yere ulaşana kadar sayısız sahibin elinden geçerek kıta değiştirmiştir. Afrika'ya gemilerle cam boncuklar taşınmış ve bu cam boncuklar para birimi veya hediye olarak kullanılmıştır (Ackam, 2013). Sahra Çölü'nün güneyinde yer alan Sahra Altı Afrika bölgesi, boncuk yapım alanlarına dair kanıtlar sunmakta ve camın varlığı genel olarak; önceleri Orta Doğu ve Hindistan'dan, sonraları ise Portekiz, Hollanda ve Venedik'ten gelen cam boncukların 
ithalatından oluşmaktadır. (History of glass in sub- Saharan Africa, Web, 2015). Dolayısıyla "Afrika Boncuğu" terimi, Afrika kıtasındaki yerli halkın kendi ürettikleri boncukların yanı sıra; literatürde "Ticaret Boncukları" olarak adlandırılmış Afrika'dan çıkmış veya Afrika'ya gelmiş bu boncuklar için de geçerlidir ve eski ticaret boncukları hâlâ iç ticarette kullanılmaktadır.

Günümüzde de Afrika kültüründe boncuk geleneği hâlâ devam etmektedir ve neredeyse Afrika'daki her etnik grup, boncukların çeşitli türlerini çeşitli amaçlar için kullanmaktadır. Örneğin Eski Kongo İmparatorluğu'nda bir genç kız ergenliğe girdiğinde "Dipo" adı verilen ergenlik töreni yapılmaktadır. Genç kızlar bu törende geleneksel olarak bellerinin etrafına "Bel Boncukları" olarak adlandırılan birden çok cam boncuk dizelerini takmaktadırlar. Takılan bu cam boncuklar da kadınlığın doğurganlık döngüsünün başlangıcını sembolize etmektedir. Ayrıca Gana'da bulunan Krobo toplumundaki boncuklar ise, hâlâ doğum, evlilik ve ölüm gibi törenlerde önemli bir rol oynamaktadır.

Afrika cam boncuklarının türleri çok fazladır ve birçoğu yöresel beğenilere göre ve kendilerine özgü yeniden dekore edilmişlerdir. Bu yüzden cam boncuk çeşitliliği oldukça karışıktır (The Basics of African Beads, Web, 2015). Afrika' da yaşayan kişiler yaptıkları çeşitli şekillerdeki cam boncuklarının düzenleme türleri, renklendirme biçimleri ve bir araya getirme yöntemleri sayesinde, yazılı dilin yokluğunda karmaşık bilgileri bu yolla ifade etmişlerdir. Dahası bir kimlik aracı olarak da hizmet eden bu sembolik cam boncuklar yaş, medeni durum ve ekonomik varlık gibi bilgileri de dile getirmiştir (The History of African Beads, Web, 2015). Dolayısıyla bu özellikleriyle Afrika'daki cam boncukların, farklı kabilelerin ve toplulukların kültürel miraslarının sergilenmesinde de önemli rol oynadığı görülmektedir.

\section{Afrika'da Cam Boncuk Üretimi}

Genellikle ufak boyutlarda ve birçok renkte var olan cam boncuklar, günlük hayatta hemen hemen her yerde karşımıza çıkmaktadır. Tek tip üretilen cam boncuklar ipe dizilmesi için ortalarından delinmiş formdadırlar. Ancak geçmişten gelen cam boncuklar genellikle boru, fıçı ve disk şeklindedirler. O günün teknolojisi ve kullanılan hammaddeler hakkındaki sınırlamaları yansıtmaktadır. Hemen hemen her toplum, bir boncuk veya hammadde üretmek için gerekli minimum teknolojiye sahiptir ve boncuk üretiminin teknik açıdan gelişmişliği ise, genellikle 


\section{SDÜ ART-E}

Güzel Sanatlar Fakültesi Sanat Dergisi

toplumun genel teknolojik düzeyini yansıtmaktadır (Dubin, 2009). Dolayısıyla “ilk camın üretimi, tarih boyunca özellikle çevresel ve kültürel ihtiyaçlara uyum sağlaması amacıyla her bölgede değişiklik göstermiştir" (History of glass in sub-Saharan Africa, Web, 2015). Geçmişte kullanılan ilkel yöntemler ya da günümüzdeki oldukça ilerlemiş teknoloji ile üretilen camın en önemli özelliği saydam olmasıdır. Ancak ilk camcılık örnekleri saydam olmadıkları için boncukçuluktaki camın saydamsızlığı bir anlamda zorunlu olmuştur. Dolayısıyla camdaki saydamlık ise daha ileri tarihlerde sağlanabilmiştir (Osamba, 2012).

Afrika'da cam boncuk yapımında ise; yerel, toplumsal ve/veya ekonomik nedenlere bağlı olarak değişen birçok araç-gereç kullanıımıştır. Dolayısıyla ekonomide yaşanan kısıtlılık yüzünden özgün, pratik, yaratıcı ve farklı çözümler oluşturularak, yokluğun içerisinde var olmaya çalışan insanların cam boncuk üretimini gerçekleştirdikleri görünmektedir.

Cam boncuk yapımında kullanmak üzere bazı basit araçlar ve gereçler geliştirilmiştir, ancak yazılı kaynaklarda bu araç ve gereçlerle ilgili bilgilere yeteri kadar yer verilmediğinden dolayı birçoğunun belirli bir ismi yoktur ve bu yüzden araştırmacılar da onlara açıklayıcı olması açısından uygun isimler kullanmışlardır (Avotri, 2009:93), (Görsel 1).

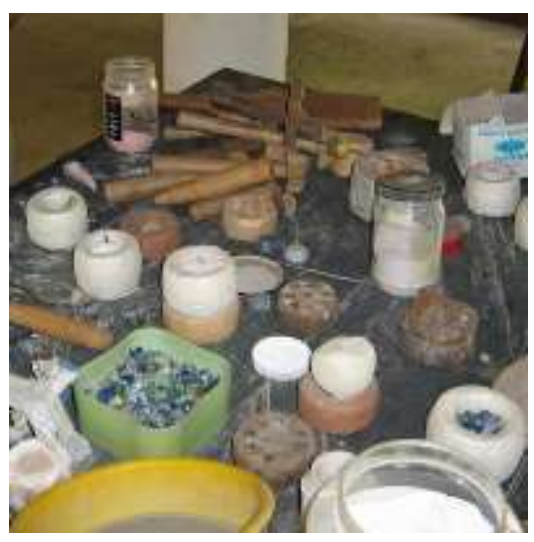

Görsel 1. Cam boncuk yapımında kullanılan malzemeler

Afrika'da cam boncuk üretiminde kullanılan en yaygın yöntemlerden birisi de "kuru dolgu (Dry-Core) cam tozu yöntemi” dir ve bu yöntem genel olarak; cam boncuk kalıplarının hazırlanması, cam parçalarının kırılarak toz haline getirilmesi, elekten geçirilmesi, cam tozunun pigment ile renklendirilmesi, hazırlanan cam tozlarının kalıplara doldurulması, pişirimin yapılması, bazı cam boncuklara dekorlama yapılarak ikinci pişirimin yapılması ve son olarak da 
temizleme/parlatma uygulamalarının yapılması aşamalarından oluşmaktadır. Bu yöntem sayesinde Afrika halkı farklı renklerde ve desenlerde özgün cam boncuklar üretmişlerdir.

Kuru dolgu (Dry-Core) cam tozu yönteminin yapım süreci ise şöyledir; ilk olarak, cam boncukların şekilleneceği kalıpların hazırlığı ile başlanır ve nehir kenarındaki bir çamur havuzundan kil toplanarak tamamen kurumaya bırakılır. Böylece kökler, yapraklar, odun ve çakıl gibi istenmeyen materyalleri ayıklamak daha kolay hale gelir. Sıradaki işlem kili iyi bir toz haline gelene kadar dövmektir. Sonra dövülmüş kil istenmeyen materyallerden arındırılması amacıyla bir elekten geçirilir. Daha kolay şekil verilebilmesi için toz halindeki kile biraz su eklenir. Kil, yumrular halinde ayrılır ve içinde hava boşlukları kalmaması için iyice yoğrulur. Sonra bu yumrular birleştirilir ve tekrar yoğrulur (Agye, Adu-Agyem and Steiner, 2013). Kil kullanıma hazır hale geldikten sonra, üretilecek olan cam boncukların boyutlarına göre spatula ya da herhangi bir kesme aleti yardımıyla standart kalınlıkta düz levhalar halinde kesilir. Bir sopa kullanılarak yüzeyi düzleştirilir. Kalıp deri sertliğine ulaştığı zaman çivi benzeri oyulmuş bir tahta parçasıyla (foa) (Görsel 2) oyuk açmak için kalıbın üzerine dikkatlice 90 derece açı ile bastırılır ve yapılacak boncuğa göre farklı boyut ve şekillerde oyuklar oluşturulur.

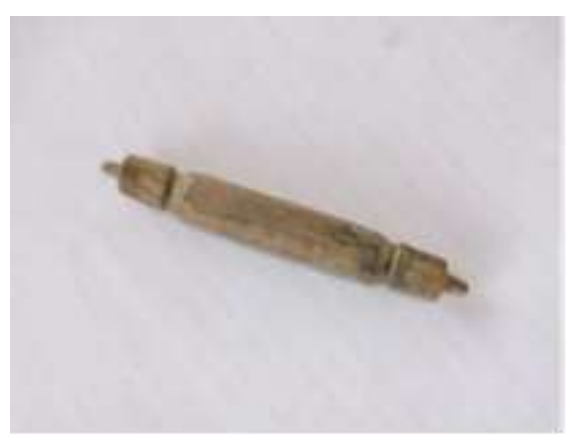

Görsel 2. "Foa” Olarak Adlandırılan Yerel Ahşap Parçası. 


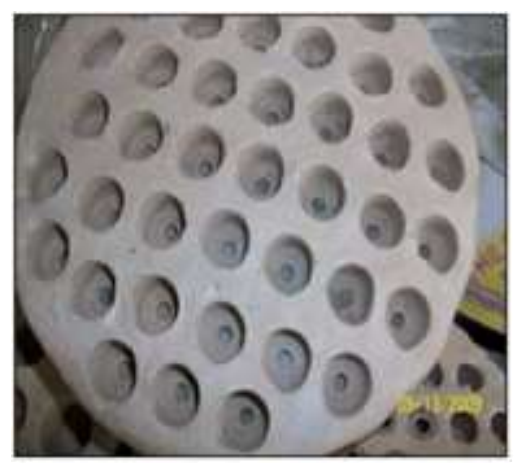

Görsel 3. Boncuk dökmek için kalıplar.

Bu yöntemle birkaç kalıp daha yapılır ve kalıplar ilk olarak oda sıcaklığında birkaç gün kurumaya bırakılır. Daha sonra kuruyan kalıplar kullanıma hazır hale gelmesi için yaklaşık1000 derecede pişirilir. Bu aşamada monyak yaprağı sapları hazırlanır ve kurumaya bırakılır.

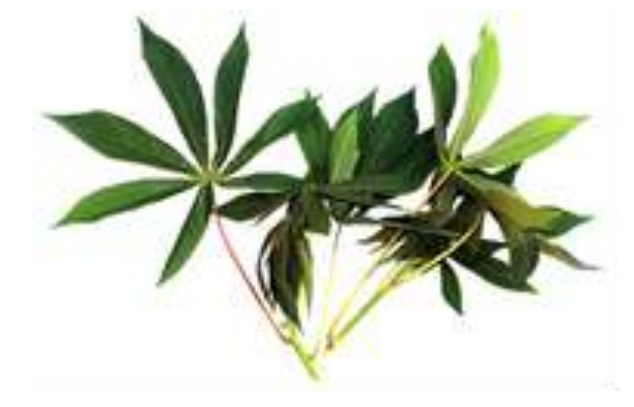

Görsel 4. Manyok (Cassava) yapraklarının sapları.

Daha sonra camın yüzeye yapışmasını önlemek için yüzeyi örtücü bir kıvamda kil solüsyonu hazırlanır. Kalıplar bu kil solüsyonuna daldırılır ve kurumaya bırakılır. Eğer yüzey tam olarak kapanmadıysa bu eylem birkaç kere tekrarlanır. Kalıplar kuruduktan sonra monyak yaprağı sapları eşit boyda kesilir ve ip geçirilecek boşluğu yaratmak için kalıptaki büyük oyukların içindeki alçak oyuklara yerleştirilir (Görsel 5), (Agye, Adu-Agyem and Steiner, 2013).

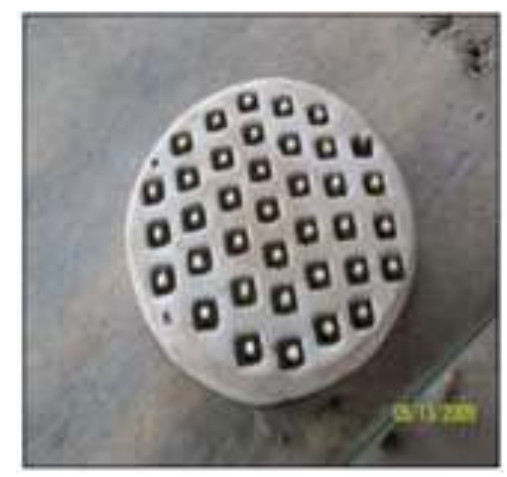

Görsel 5. Manyok yaprağııın saplarının yerleştirildiği kalıp. 
Manyok yaprağının sapları çok lifli olduğundan, fırında camlar erirken çabucak yanacaktır ve boncuğun rengini etkilemeden deliklerinin açılmasını sağlayacaktır (Avotri, 2009:114). Daha sonra eski arta kalan cam şişelerin ve diğer cam kırıklarının metal veya ahşap bir havanda (Görsel 6) kırılmasıyla cam boncuk yapım süreci devam etmektedir. "Boncuk yapanlar camı kırar, eritir ve yeni boncuklar yaparlar" (Osamba, 2012).

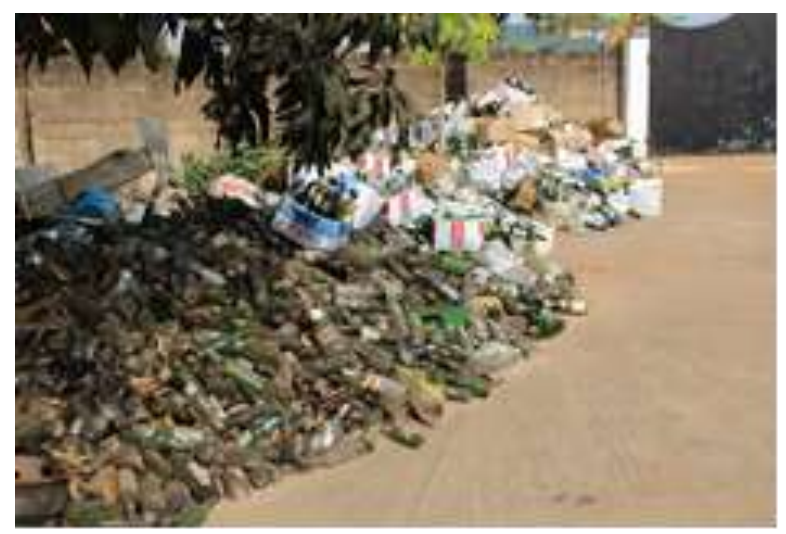

Görsel 6. Cam boncukları yapmak için şişeler.

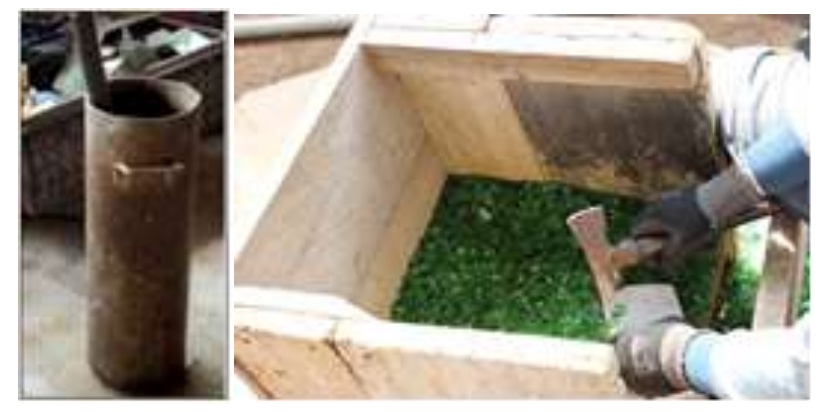

Görsel 7. Metal-Ahşap havan.

Kırık şişeler boncuğun tasarımına göre farklı renklere ayrılır ve her renk teker teker havana dökülerek ince bir toz haline gelene kadar havan eliyle iyice dövülür. Daha sonra dövülen cam, farklı tane boylarını birbirinden ayırmak ve cam yapımı için ideal hale gelmesi için elekten geçirilerek kullanıma hazır hale getirilir. 


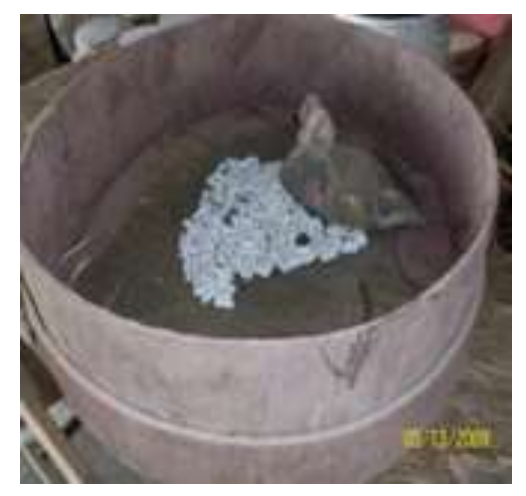

Görsel 8. Dövülen camları elemek için elek.

İyice ezilmiş cam tozu, cam boncuk yapımında temel materyaldir. Camın şeffaflığını belirlemede camın tane büyüklüğü önemli bir unsurdur. Örneğin, camı ne kadar çok toz haline getirirseniz cam boncuk o kadar opak, tane büyüklüğü arttıkça da camın rengi o kadar saydamlaşacaktır. Ancak 1980 'lerin ortalarında, camın saydam kalması sağlanmış ve kırılmış geri dönüşüm camlarından ve atık cam şişelerden Yarısaydam Boncuklar, Saydam Boncuklar ve Geri Dönüştürülen Antika Cam Boncuklar üretilmiştir (Gott, 2014:22). Yarı Saydam Boncuklar, camı toz haline getirmeden küçük boyutlardaki cam parçalarından yapılmaktadır. Bu üretimde de atık cam şişeler kullanılır ve camların tane boyutları toz camdaki kadar ince olmaz. Büyük Saydam Boncuklar, tamamı aynı boyutlarda kesilmiş küçük cam parçaların tek parça halinde kalıba yerleştirilmesiyle yapılmaktadır (Krobo beads from Ghana, Web, 2015) ve pencere camları ya da cam şişeler gibi saydam camlardan üretilirler. Ancak bu cam boncukların boyutları büyük olduğu için hazırlanacak kalıplar da bir o kadar büyük olmalıdır. Geri Dönüştürülen Antika Cam Boncuklar ise; üretim alanlarında kırılmış eski boncuk parçalarından ve kırık antika cam boncuklardan yapılmaktadır.

Camı iyice ezdikten ve elekten geçirdikten sonra sırada renklendirme aşaması vardır. Cam boncuğun rengi bu aşamada belirlenir ve bu aşamada boncuk için hazırlanan cam tozuna renk eklenir. Farklı renklerde cam tozu elde etmek için pigment veya seramik boyası kullanılmaktadır. Yarı Saydam ve Saydam Boncukların yapımında cama pigment veya seramik boyası eklenmez, çünkü kullanılan cam şişenin rengini almaktadır. Ancak renkli cam şişelerin kendi renkleri dahi ileri aşamalarda solmuş olacağı ve üreticinin ihtiyacı olan parlak renkleri sağlayamayacağı için renklendirme yapılması gerekmektedir (Avotri, 2009:105). Bu yüzden 
çeşitli tasarımların ve birçok farklı renklerdeki dekoratif desenlerin yaratılmasında; seramik boyaları veya pigmentler, kırık cam boncuklar veya çeşitli kaynaklardan elde edilen farklı renklerdeki cam kırıklarının öğütülmüş tozları kullanılmaktadır.

Bir sonraki aşamada; iyice öğütülmüş olan cam, manyok saplarının yerleştirildiği kalıplara doldurulur (Görsel 9). Ancak yarı şeffaf boncukların deliklerini oluşturmak için bu manyok sapları kullanılmamaktadır. Kalıbın içi tamamen kırık cam parçalarıyla doldurulur (Görsel 10). Bu tür boncukların delikleri pişirme aşamasında faklı yöntemle yapılmaktadır.

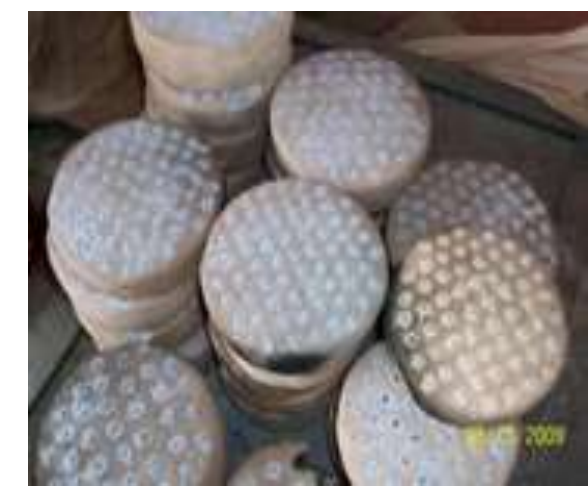

Görsel 9. Fırınlanmaya hazır doldurulmuş kalıplar.

Daha sonra Toz Cam Boncuk kalıplarındaki boşlukların dolduğundan emin olmak için kalıp iyice sallanır. Gerekirse boşlukları doldurmak için biraz daha cam tozu eklenebilir ve son olarak da kalıbın yüzeyindeki fazlalıklar temizlenir.

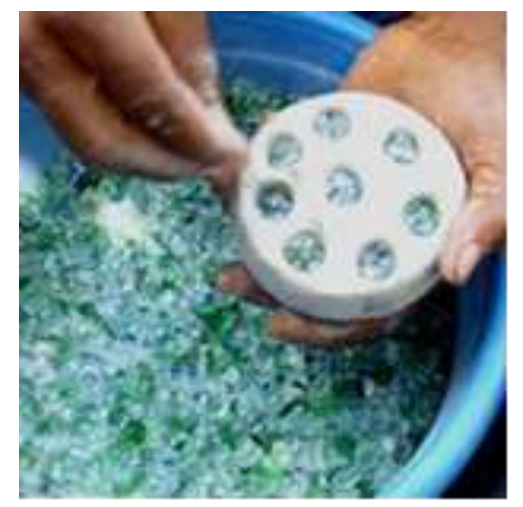

Görsel 10. Yarı şeffaf cam boncuk kalıplarının cam kırıklarıyla doldurulması.

Fırınlanmaya hazır doldurulmuş kalıplar sudan uzak tutularak kuru ortamda muhafaza edilmelidir. Çünkü nem, kalıpların yapısını etkileyerek fırınlama aşamasında çatlamasına sebep 
olabilir. Sonucunda da oluşan çatlaklar tasarımın bozulmasına yol açacaktır. Ayrıca doldurulan kalıpların kırılmaması için de dikkatli bir şekilde tuğla yığma yöntemiyle üst üste gelecek şekilde yerleştirilerek muhafaza edilir (Agye, Adu-Agyem and Steiner, 2013).

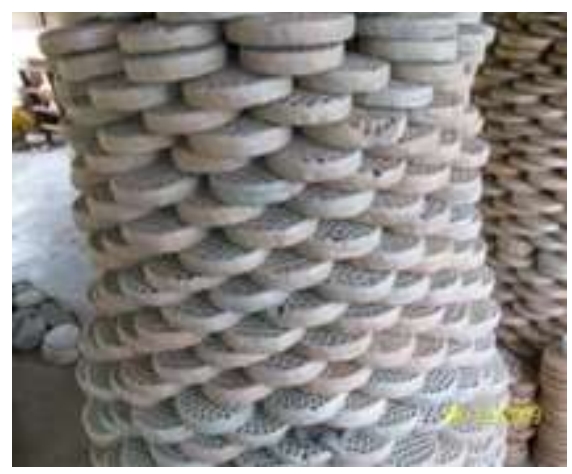

Görsel 11. Paketlenmiş kalıplar.

Fırınlama aşamasında; cam boncukların pişirimi termit kilinden yapılmış geleneksel bir fırında yapılmaktadır. Doldurulan kalıplar önceden ısıtılarak belli bir sıcaklığa ulaşmış olan bu fırına yerleştirilir ve pişirimleri gerçekleştirilir.

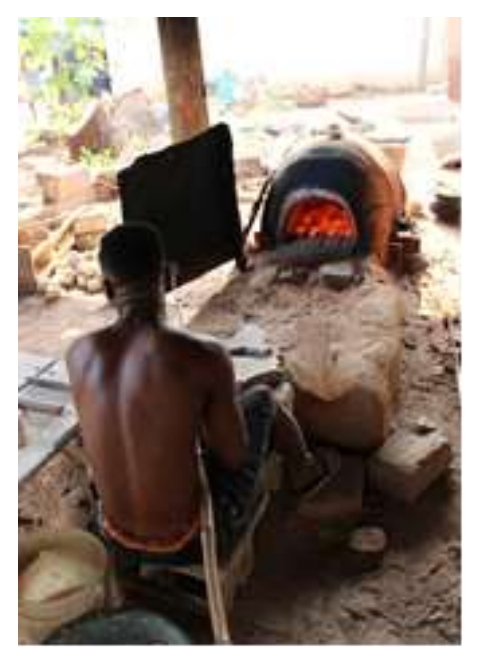

Görsel 12. Boncukların fırınlanması.

Cam boncuk üretiminin en temel araçlarının başında yerel malzemelerden üretilen fırınlar gelmektedir. Örneğin Gana'da kullanılan fırınlar (Görsel 13), çoğunlukla balçık haline getirilmiş topraktan ve eski metal kamyon parçalarından yapılmıştır. Eski metal kamyon parçaları kaide olarak kullanılmıştır. Fırın ateşi genellikle odun ateşiyle desteklenmektedir ancak Floransa ve çevresindeki etkileri azaltmak için, yeni bir yöntem olan doğal gaz kullanılmaya 
başlanmıştır (Krobo beads from Ghana, Web, 2015). Fırının ters yönde iki girişi bulunmaktadır. Girişlerden biri fırının ön tarafındadır ve kalıplar bu alana yerleştirilir. Genellikle korunaklı tarafta bulunan bu giriş boncuk üreticisinin boncuk kalıplarını fırına verdiği, gözlemlediği ve fırından çıkarttığı kısımdır. Diğer giriş ise fırının arka tarafında bulunmaktadır ve bu alanda ateş yakılmaktadır. Genel olarak bu alan ön girişin yani yükleme ağzının altında yer alır, bu sayede pişmesi gereken ürünler ateşin üstünde kalmaktadır (Avotri, 2009:95).

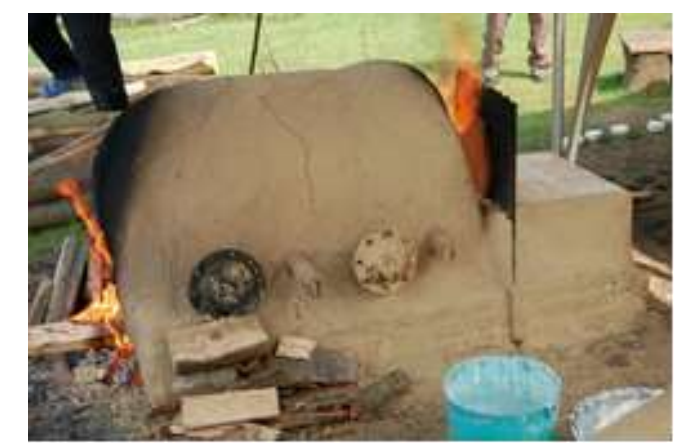

Görsel 13. Balçık haline getirilmiş topraktan yapılmış fırın.

Afrika'da bu fırınların yapımında doğadaki birtakım oluşumlardan da faydalanarak yerel malzemeler kullanıımıştır. Cedi Boncuk Endüstrisi'nin yöneticisi Kudjo Owusu'ya göre; fırın inşa etmek için kullanılabilecek en iyi kilin, termitlerin tepelerinden (karınca yuvası tepeleri) geldiğidir. Çünkü bu tür bir kilin en yüksek ısılara bile dayanabileceğine inanmaktadır. Ancak Baş Materyal Araştırma Bilim Adamı ve CSIR-BRRI'ın İnşa Materyalleri Bölümünün Başı J.K. Boadi ise bu iddiaya farklı yaklaşmaktadır. Ona göre akkarınca tepelerinden alınacak kilin bu kadar iyi olmasının sebebi bu değildir. Akkarıncalar kili yerinde tutmak için kimyasal bir yapıştırıcı tükürerek, akkarıncaların tepelerini inşa ettikleri kile kimyasal ve organik bileşenlerine katkıda bulunabileceğini belirtmiştir. Fakat bu tükürüğün kili ateşe dayanıkı bir hale getirecek bir kimyasal yapıda olmadığı bilinmektedir. Akkarınca tepelerinin oluştuğu toprağın temelinde bol miktarlarda kum bulunduğunu belirtmiştir ve bunun doğruluğu da Rogers ve arkadaşları (1999) tarafından kanıtlanmıştır (Avotri, 2009:100). Bu da bir anlamda bu killerin, kumla birlikte ateşe karşı direnç kazandığı sonucunu ortaya çıkarmaktadır. Daha sonra fırın, inşa edildikten sonra ikiüç hafta kadar kurumaya bırakılmalıdır.

Fırın yapımı tamamlandıktan sonra fırın ateşlemesi yapılır ve cam boncukların şekillenmesi için gerekli olan ısı sağlanmaya çalışılır. Genel olarak, özel içeriklere sahip camların 
dışında birçok cam yaklaşık $900^{\circ} \mathrm{C}$ sıcaklığında erimektedir. Bu işlem fırının sıcaklığına bağlı olarak "Toz Cam Boncukların şekillenmesi için yaklaşık 650-800 C'de 20-30 dakika sürede bekletmek gerekmektedir (The art of making traditional glass beads in Ghana, Web, 2015)". Yarı Şeffaf Boncuklar 850-1000 ${ }^{\circ} \mathrm{C}$ arasında bir sıcaklıkta 35-45 dakika ve Şeffaf Boncuklar ise, $100{ }^{\circ} \mathrm{C}$ ile $800{ }^{\circ} \mathrm{C}$ arasında bir sıcaklıkta 45 dakika kadar bekletilerek şekillendirilir. Ancak yüzeyi dekorlanan renkli boncuklara ikinci bir fırınlama yapılmaktadır (Agye, Adu-Agyem and Steiner, 2013:109).

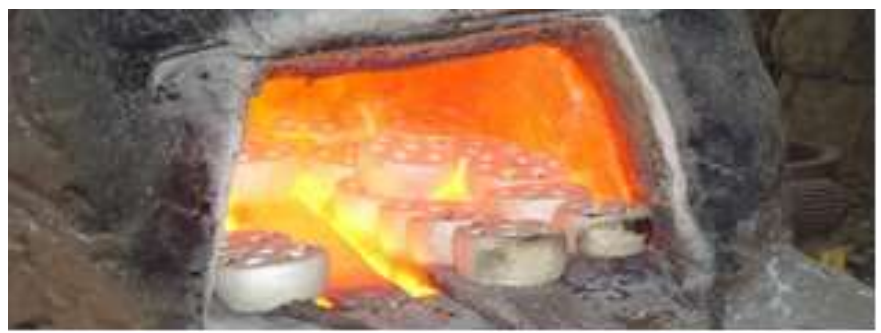

Görsel 14. Fırınlanmış olan kalıplar.

Eriyik hale gelen cam belli bir olgunluğa geldiğinde parlak bir renk tonuna ulaşır. Bu süreden sonra kalıpların fırından çıkartılması gerekmektedir. Çünkü herhangi bir gecikme aşırı pişmeye neden olacağından, boncukta matlaşmaya ve renginin bozulmasına sebep olur. Bu da istenmeyen bir durumdur ve ateş söndürülür. Bu süreçten sonra fırınlama işlemi tamamlanır ve kalıplar soğumaya bırakılır. Ancak bu süreçte dikkat edilmesi gereken en önemli nokta; kalıpların hemen dışarıya çıkartarak sıcak haldeki cam boncukların soğuk havaya maruz bırakılmamasıdır. Dolayısıyla cam boncukların çatlamaması için kalıpların yaklaşık 48 saat boyunca yavaşça soğutulmaları gerekmektedir.

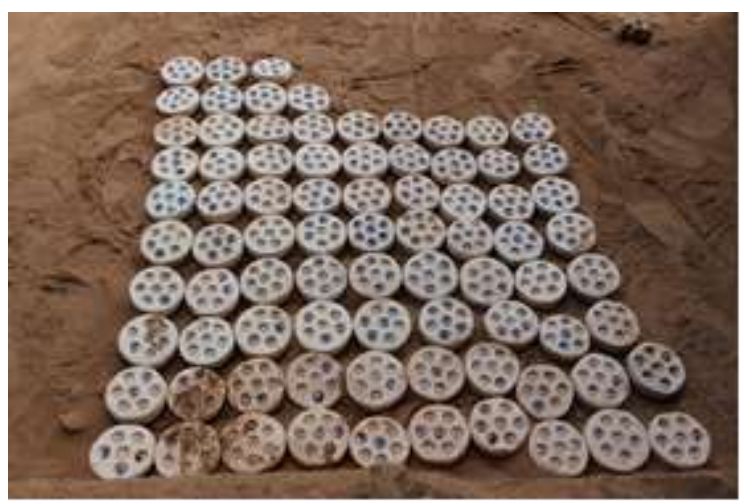

Görsel 15. Kalıplardaki yeni cam boncuklar. 
Soğuyan boncuklar kalıplardan çıkartıır ve yıkanmaları için bir su kabına konulmaktadır. Daha sonra iyice yıkanan cam boncuklar bir süre güneş altında kurutularak süslemeye hazır hale gelmektedirler (Görsel 16).

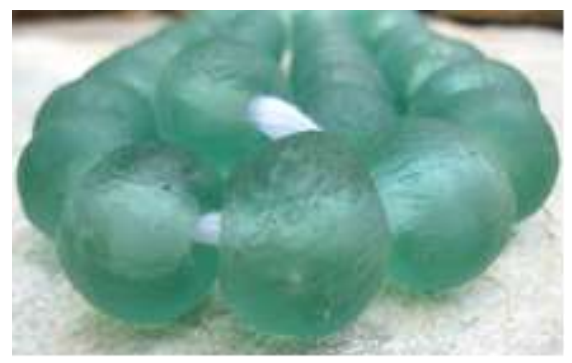

Görsel 16. Yarı saydam cam boncuklar.

Monyak sapı kullanılmayan Yarı Şeffaf ve Şeffaf Boncukların delikleri, pişirme aşamasında elde edilmektedir. Bu süreçte ise; kalıplardaki cam sıcaktan kızarınca kalıp fırından çıkartılır ve (Görsel 17) erimiş haldeki camın merkezine bir tığ yardımıyla bastırılarak delik açılır. Bu aşamada iki tane tığ kullanılır; bir tığ yerdeki kalıbı tutarken, diğeri ise ortam ısısına bağlı olarak sertleşmeye başlayan ve kalıba kaynaşmış olan boncuğu döndürmek için kullanılır (The art of making traditional glass beads in Ghana, Web, 2015). Oldukça beceri gerektiren bu yöntem hızlı bir şekilde uygulanmalıdır.

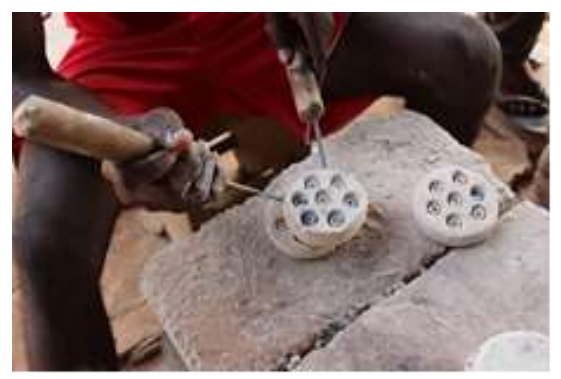

Görsel 17. Boncuklara deliklerin açılması.

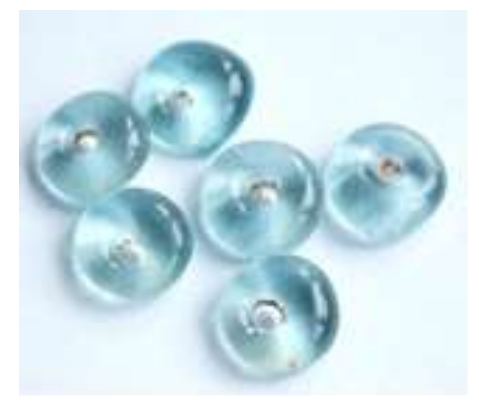

Görsel 18. Delinmiş saydam boncuklar. 
Geri Dönüştürülen Antika Cam Boncukların yapımında kırılmış boncuk parçaları kullanılır. Kırılan parçalar kalıp içerisine yerleştirilir ve fırınlanır. Kalıp içerisindeki cam parçaları eridiğinde ise, tek bir boncuk şeklinde görünürler ve her boncukta mozaiği andıran renkler ortaya çıkmaktadır (Ackam, 2013:40-41).

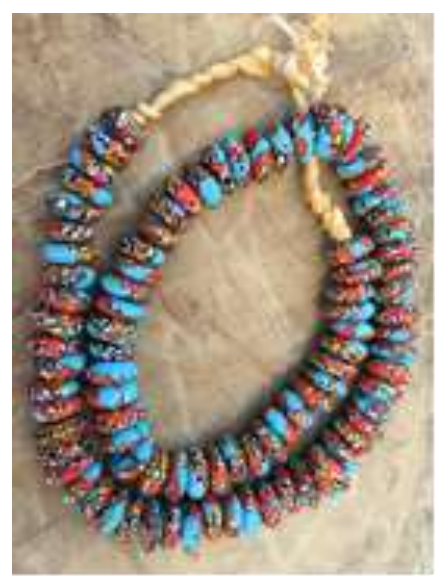

Görsel 19. Geri dönüştürülen antika cam boncuklar.

Dekorlama aşamasında ise ilk olarak, bir miktar toz hâline getirilmiş cam alınır ve içerisine pigment ve su ilave edilerek macun kıvamına gelene kadar iyice karıştırılır (Avotri, 2009:108). Daha sonra; cam boncuklar iğne, şiş veya sivri bir tahta sopa yardımıyla (Görsel 20) bu hazırlanan karışımla dekore edilir.

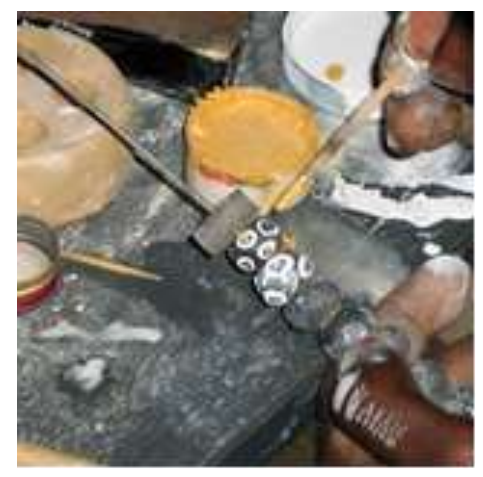

Görsel 20. Boncukların dekorlanması.

Dekore edilen boncuklara ikinci pişirim yapılır. Bunun sebebi ise uygulanan dekorların sabitlenmesi içindir. Boyanan yüzeyler kuruduktan sonra cam boncuklar kalıba tekrar yerleştirilir ve fırınlanır. Bu aşamadaki pişirim düşük ısılarda gerçekleştirilir ve pişirim süresi aşırı ısınmadan kaynaklı boncuğun çökme, hatta deliklerin kapanmaması için en fazla 15-20 dakika 
kadar sürmektedir. Ayrıca yine de boncuk deliklerinin kapanmaması için ilk ateşlemedeki gibi kalıplara tekrar manyok yaprak sapları yerleştirilir. Daha sonra boncuğun yüzeyine uygulanan bu karışım ateş içindeyken eriyerek boncuklarla birleşir (Avotri, 2009:110).

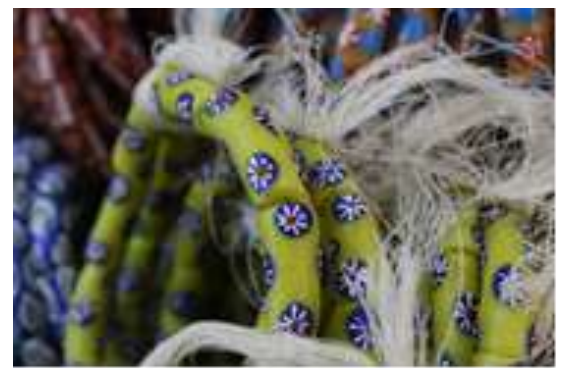

Görsel 21. Boyanmış cam boncuklar.

İkinci ateşlemeden sonra kalıptan çıkartılan boncukların yüzeyi mat ve kirlidir, bu yüzden temizlenmeleri gerekmektedir. Artık bu aşamada yıkanmış olan cam boncuklar törpü taşı (Görsel 22), su ve kum ile 15 dakika kadar üzerindeki pislikler alınıp kenarları yumuşatılır, parlatılır (Görsel 23) ve süreç tamamlanır.

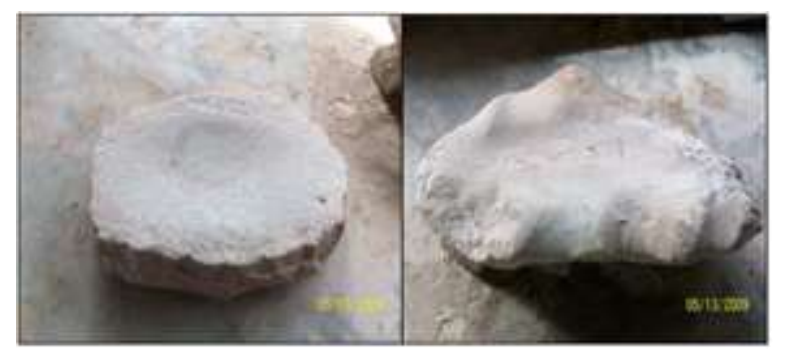

Görsel 22. Boncukları yumuşatmak için kullanılan törpü taşları.

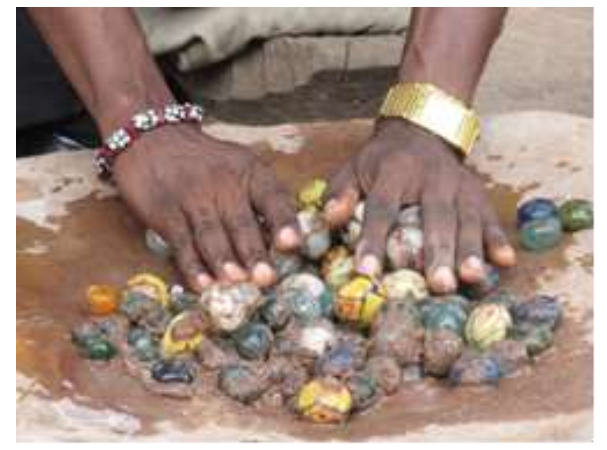

Görsel 23. Gana boncuklarının parlatılması.

Genel olarak yapım aşamalarının anlatıldığı kuru dolgu yöntemi, kalıpta şekillendirilmiş cam tozu tekniğinin iki farklı uygulamasından bir tanesidir. Bu yöntem Afrika'nın farklı 
bölgelerinde ve farklı zamanlarında cam boncuk yapımı için çokça kullanılmıştır. Dolayısıyla bu yöntemle yapılmış olan cam boncuk türleri, yöresel kullanımlarına göre gruplandırılmıştır. Yaygın örnekleri ise; Akoso Boncukları, Meteyi Boncukları, Krobo Boncukları'dır.

Akoso Boncukları, 1950'lerden kalma en eski Gana cam tozu boncuk yapımının ilk örnekleri arasındadır ve Batı Afrika Gana'da bulunan Toz Cam Boncuğunun son derece değerli bir türüdür.

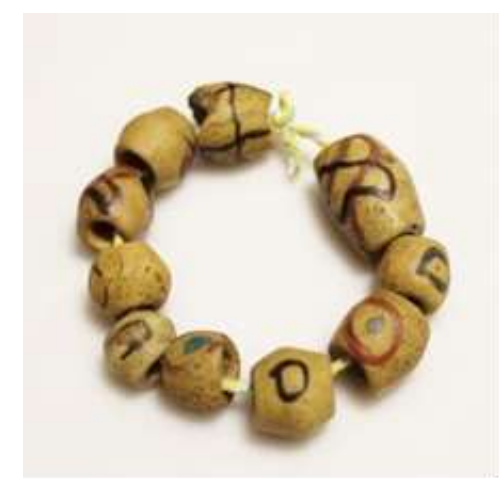

Görsel 24. Akoso boncukları.

Ashanti'de yaygın olan Meteyi Boncukları, yapım tekniğinden dolayı pürüzlü ama neredeyse tam olarak erimiş bir yapıya sahiptir ve boncukların üzerinde çubukların boyunda şeritleri bulunmaktadır. Yatay kalıplama yöntemiyle üretilen bu boncuklarda boylamsal katmanlar sık sık gözlemlenebilir. Çünkü yatay kalıplamada pişirme esnasında zemine değen kısım yandır ve değen tarafın yüzeyi de pürüzlüdür. Daha sonra bu pürüzler oluklu taşlarla düzleştirilmiştir.

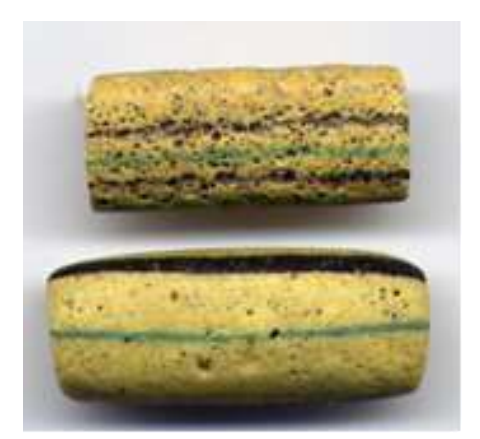

Görsel 25. Ashanti, Meteyi boncukları. 
Krobo Boncukları ise, Afrika'daki geleneksel boncuk sanatlarından biri olarak yer almaktadır (Görsel 26). Bu cam boncuklar Gana'da etnik bir grup olan Krobo halkı tarafından üretildiklerinden dolayı Krobo Boncukları olarak da bilinirler (Sandcast Beads, Web, 2015).

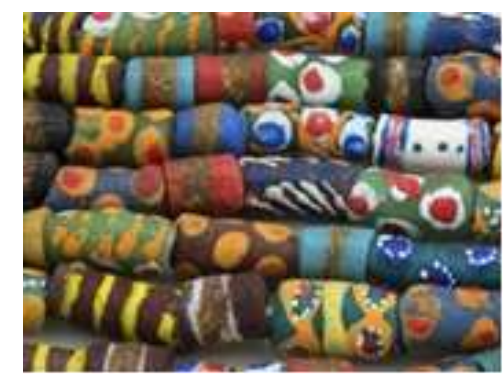

Görsel 26. Krobo boncukları.

\section{Sonuç}

Bu çalışmada, Afrika'daki cam boncuk tarihi incelenmiş olup; Afrika kültüründe oldukça önemli bir yere sahip olan boncukların, geçmişteki ve günümüzdeki etkilerini ortaya koymaktadır. Araştırma süresince yazılı kaynaklardan faydalanarak Afrika'da boncuk üretiminde kullanılan "kuru dolgu (Dry-Core) cam tozu yöntemi, bu yöntem ile oluşturulan cam boncukların yapım süreci ve kullanılan araç ve gereçler hakkında bilgiler toplanmıştır. Dolayısıyla bu çalışma, Afrika'daki zengin bir boncuk çeşidini de ortaya koymaktadır.

Geçmişten günümüze sürekli yaşamlarının içinde var olan Afrika Boncukları, Afrika halkı için farklı malzemelerle de çeşitlenen kültürel bir olgu olmuştur. Bu yüzden çok fazla çeşitlilik göstermektedir. Ancak Afrika'daki bu boncuklar "cam boncuk" olarak sınıflandırıldığında, birçok üretim tekniği karşımıza çıkmaktadır ve cam boncuk üretiminde kullanılan en yaygın yöntemlerden birisi de "kalıpta şekillendirme tekniği" dir. Bu teknik, camın toz haline getirilmesi ve birbirinden farklı yöntemlerle kalıplanması temeline dayanmaktadır. Bu teknikle yapılmış olan cam boncuklar da genel olarak "Kalıpta Şekillendirilmiş Cam Boncuklar" olarak adlandııımıştır. Ancak bu yapım tekniğinin malzemeye ya da fırın tekniklerine bağlı olarak ve yöresel açıdan da her ustaya göre çeşitlendiği gözlemlenmiştir. Bunlar arasında; cam boncuk yapımında kullanılan kalıbın iyice öğütülmüş cam tozunun tabakalar halinde doldurulmasından oluşan Kuru Dolgu Cam Tozu Yöntemi de bunlardan bir tanesidir. Hem Afrika kültürüne hem de 
diğer kültürlere farklı değerler katmasının yanında, önemli bir süs objesi de olan bu cam boncuklar, artık çağımızda çağdaş bir sanat objesi olarak varlığını korumaktadır.

\section{Kaynakça}

Ackam, N. L. T. (2013). Amplifying the Ghanaian Bead through Publication Design, Doctoral dissertation, School of Graduate Studies, Kwame Nkrumah University of Science and Technology, Kumasi.

Agye, I. K., Adu-Agyem, J. and Steiner, R. (2013). Exploring Traditional Glass Bead Making Techniques in Jewellery, Journal of Science and Technology (Ghana), 32 (3), p.103-112.

Avotri, N. V. K. (2009). The Bead Culture among the Krobo of Ghana, Doctoral dissertation, School of Graduate Studies, Kwame Nkrumah University of Science and Technology, Kumasi.

Dubin, L. S. (2009). Contemporary Beads and Jewelry, Ornament, 33 (2).

Dubin, L. S. (2009). The History of Beads: from 100,000 B.C. to the Present, New York: Abrams.

Gott, S. (2014). Ghana's Glass Beadmaking Arts in Transcultural Dialogues, African arts, 47 (1), p.10-29.

Osamba, J. O. (2012). Ethnicity and Social Change in Contemporary Africa: An Overview, Journal of Education and Social Sciences, p.3.

\section{İnternet Kaynakları}

History of Glass in Sub-Saharan Africa, (2020). http://en.wikipedia.org:https://en.wikipedia. org/wiki/History_of_glass_in_sub Saharan_Africa, Erişim tarihi: 13.10.2015.

Krobo Beads from Ghana, beadmuseum.wordpress.com: https://beadmuseum.wordpress.com /2010/08/15/krobo-beads-from-ghana/, Erişim tarihi: 13.10.2015.

Life on a String: 35 Centuries of the Glass Bead, Corning Museum of Glass: http://www.cmog. org/article/life-string-35-centuries glass-bead, Erişim tarihi: 21.07.2015.

Sandcast Beads, The Beadchest, http://www.thebeadchest.com/sandcast-beads-94, Erişim tarihi: 23.10.2015.

The art of making traditional glass beads in Ghana, ghanacraft.com: http://www.ghanacraft.com/bead making.htm, Erişim tarihi: 13.10.2015. 
SDÜ ART-E

Güzel Sanatlar Fakültesi Sanat Dergisi

Haziran'20 Cilt:13 Sayı:25

ISSN 1308-2698

The Basics of African Beads, The Beadchest: http://www.thebeadchest.com/african-beads, Erişim tarihi: 23.10.2015.

The History of African Beads, Stream Africa: http://streamafrica.com/culture/the-history-ofafrican-beads/, Erişim tarihi: 20.07.2015.

\section{Görsel Kaynaklar}

Görsel 1. Cam boncuk yapımında kullanılan malzemeler,

http://sankofa.com.au/images/Beads1-lg.jpg, Erişim tarihi: 23.04.2016.

Görsel 2. "Foa" Olarak Adlandırılan Yerel Ahşap Parçası,

http://ir.knust.edu.gh:8080/bitstream/123456789/5632/1/Agyei.pdf, Erişim tarihi: 29.10.2015.

Görsel 3. Boncuk dökmek için kalıplar,

http://ir.knust.edu.gh:8080/bitstream/123456789/5632/1/Agyei.pdf, Erişim tarihi: 29.10.2015.

Görsel 4. Manyok (Cassava)yapraklarının sapları, https://sbene.com/488/health-benefitscassava-leaves/, Erişim tarihi: 12.03.2019.

Görsel 5. Manyok yaprağının saplarının yerleştirildiği kalıp, http://ir.knust.edu.gh:8080/bitstream/123456789/5632/1/Agyei.pdf, Erişim tarihi: 29.10.2015.

Görsel 6. Cam boncukları yapmak için şişeler, http://bomafrica.blogspot.com/2017/08/camocagi.html, Erişim tarihi: 12.03.2019.

Görsel 7. Metal -Ahşap havan, http://ir.knust.edu.gh:8080/bitstream/123456789/5632/1/Agyei.pdf, Erişim tarihi: 29.10.2015, http://bomafrica.blogspot.com/2017/08/cam-ocagi.html, Erişim tarihi: 12.03.2019.

Görsel 8. Dövülen camları elemek için elek, http://ir.knust.edu.gh:8080/bitstream/123456789/5632/1/Agyei.pdf, Erişim tarihi: 29.10.2015.

Görsel 9. Fırınlanmaya hazır doldurulmuş kalıplar, http://ir.knust.edu.gh:8080/bitstream/123456789/5632/1/Agyei.pdf, Erişim tarihi: 29.10.2015.

Görsel 10. Yarı şeffaf cam boncuk kalıplarının cam kırıklarıyla doldurulması, http://www.ghanacraft.com/bead-making.htm, Erişim tarihi: 13.10.2015.

Görsel 11. Paketlenmiş kalıplar, http://ir.knust.edu.gh:8080/bitstream/123456789/5632/1/Agyei.pdf, Erişim tarihi: 29.10.2015.

Görsel 12. Boncukların fırınlanması, http://bomafrica.blogspot.com/2017/08/cam-ocagi.html, Erişim tarihi: 12.03.2019. 
SDÜ ART-E

Güzel Sanatlar Fakültesi Sanat Dergisi

Haziran'20 Cilt:13 Sayı:25

ISSN 1308-2698

Görsel 13. Balçık haline getirilmiş topraktan yapılmış fırın,

https://beadmuseum.files.wordpress.com/2010/08/dsc_0496.jpg, Erişim tarihi: 13.10.2015.

Görsel 14. Fırınlanmış olan kalıplar, http://www.ghanacraft.com/bead-making.htm, Erişim tarihi: 13.10.2015.

Görsel 15. Kalıplardaki yeni cam boncuklar, http://bomafrica.blogspot.com/2017/08/camocagi.html, Erişim tarihi: 12.03.2019.

Görsel 16. Yarı saydam cam boncuklar, https://www.etsy.com/listing/185181577/africanrecycled-glass-beads-20-mm, Erişim tarihi: 28.04.2016.

Görsel 17. Boncuklara deliklerin açılması, http://bomafrica.blogspot.com/2017/08/camocagi.html, Erişim tarihi: 12.03.2019.

Görsel 18. Delinmiş saydam boncuklar, https://beadmuseum.files.wordpress.com/2010/08/dsc_0538.jpg, Erişim tarihi: 13.10.2015.

Görsel 19. Geri dönüştürülen antika cam boncuklar, https://www.etsy.com/ANTIQUERBEADS/listing/574597426/ghana-new-recycle-glass-beadafrica?utm_source=Pinterest\&utm_medium=ListingManager\&utm_campaign=Share\&utm_ter $\mathrm{m}=$ so.Imsm\&share_time $=1516671749864$, Erişim tarihi: 12.03.2019.

Görsel 20. Boncukların dekorlanması, http://sankofa.com.au/images/Beads3-lg.jpg, Erişim tarihi: 23.04.2016.

Görsel 21. Boyanmış cam boncuklar, http://bomafrica.blogspot.com/2017/08/cam-ocagi.html, Erişim tarihi: 12.03.2019.

Görsel 22. Boncukları yumuşatmak için kullanılan törpü taşları, http://ir.knust.edu.gh:8080/bitstream/123456789/5632/1/Agyei.pdf, Erişim tarihi: 29.10.2015.

Görsel 23. Gana boncuklarının parlatılması, https://upload.wikimedia.org/wikipedia/commons/3/37/Polishing_of_Ghanaian_glass_beads.J PG, Erişim tarihi: 25.02.2016.

Görsel 24. Akoso boncukları, https://colorsquare.co/products/old-ethnic-glass-beads-africanakoso-beads-jewelry-supplies-ab17, Erişim tarihi: 12.03.2019.

Görsel 25. Ashanti, Meteyi boncukları, http://beadcollector.net/cgibin/anyboard.cgi?fvp=/openforum/\&cmd=get \&cG=3383436303\&zu=3338343035\&v=2\&gV=0\& $\mathrm{p}=$, Erişim tarihi: 12.03.2019.

Görsel 26. Krobo boncukları, http://happymangobeads.com/assorted-sandcast-beads-5-25mmsc963/, Erişim tarihi: 23.04.2016. 